\title{
Investigation and analysis of the imported infant food purchase behavior In the Shanghai area
}

\author{
Jing Chen ${ }^{1, a}$, Yan-rong Liu ${ }^{2, b}$ and Xiao-rong Liü, c \\ ${ }^{1}$ School of Beijing, Beijing Wuzi University, Beijing 101149, China; \\ ${ }^{2}$ School of Beijing, Beijing Wuzi University, Beijing 101149, China. \\ A13811480429@126.com, b13811480429@126.com, '15046494907@163.com
}

Keywords: infant food; quality status;buying behavior;facing the problem;advice.

\begin{abstract}
Through the study of the quality of imported infant foods from different sources and combine survey, this paper analyzes and explores the purchase of imported infant food problems facing their solutions on the Shanghai region on the basis of introducing imported infant food quality situation on Shanghai region. This research can help consumers distinguish under limited conditions and buy the security of imported foods rightly.

Infants usually refers to children 0-3 years of age, so the groups studied in this paper for children 0-3 years old, empathy infant food means food for 0-3 years of age children(Generally referred to as the infant food in this paper). With the changing times infant food also toward diversification, and now many varieties of baby food such as: milk, rice, noodles, fruit and vegetable purees, mess, biscuits, bread, teething rings and so on.Infant is a group who is in need of protection, particularly important in the diet.The quality of infant food is directly related to whether the infants were able to grow up healthy and happy.
\end{abstract}

\section{Imported infant food consumer analysis}

According to some actual interview survey of he supermarkets, a variety of network Family Forum and consumers, there obtains some data on consumers for some imported infant food purchases, so we made the following analysis:

Most consumers choose to buy imported infant food who are high-end people, especially young families to 80,90 . The crow have the ability to accept new things and have a strong purchasing power and do not exclude contact with imported baby food, on the contrary, more or less people has some the complex of "Worship" to import food because of today's social environment.

Most consumers have a buying psychology that "high price" is the "high-quality". Due to the particularity of infant food, consumers want to give babies a better product to meet the satisfaction of the family consumption, so the high price of imported infant food becomes the best choice. Of course, brand awareness is an important factor of consumer preference, and usually good brand also has the characteristics of high prices. The most important thing is that consumers choose good brand from the imported brand.

Imported milk powder accounted for the highest portion of imports infant food consumption. Import milk powder occupies the important position in the infant food market consumption, what can be seen from stores of infant food in the cupboard. Imported milk powder accounted for half of infant food sales areas.

When some consumers choose import infant food supplement products, they are prohibitive because of high prices. The most important reason is that a food supplement as the rapid consumption of food may be replaced by homemade food,what does not like milk that is so irreplaceable. The consumers who choose to buy imported infant food supplement still occupy more than half of all the consumers in the food supplement.Faced with "high price" of food supplement, consumers do not believe the "high price" will bring "high quality",on the contrary,there is more attention to nutritional balance and beneficial to the growth factors and other aspects to consider buying imported food supplement. 
There were $40 \%$ of the respondents who purchased imported infant food said that they encountered some quality problems and the issues that food was not suitable for their own baby. The main problem is the baby after eating a touchy, allergies, diarrhea, vomiting and other adverse reactions. According to wang, interviewed her buy a German Jensen 's liver mud, threw up her baby after the use of adverse reactions, according to her the pork liver mud in open cans at the moment of smell the fragrance of the extremely rich, very seduce her appetite, but the baby is sick.

Consumers who buy imported infant food is basically do not under the guise of another man's hand, main basis is the introduction of relatives and friends. Said in according to the study of consumers to buy imported infant food and most believe that the introduction of relatives and friends have other baby tried and no adverse reactions to import infant food is the most popular, followed by some parents and children on the network BBS on netizens recommend is also considering buying one of the important factors of infant food.

Consumers would supplement certain knowledge of imported baby food before buying. In the face of a growing number of all kinds of different brands of imported infant food, consumers will usually carry on some imported infant knowledge learning, main channels and friends through the network transmission, usually with a little knowledge.

Consumers mainly choose the channel of the relative safety to buy imported infant food. The main channel or large stores, maternal and child supplies store, accounts for nearly $60 \%$. Secondly, online shopping channels, accounted for $20 \%$. And overseas act as purchasing agency has become a dark horse, accounted for $15 \%$ and proportion have been gradually rising trend.

Consumers do not blindly believe, because import infant food quality also has certain question. With this question is mainly attributed to the country for some import infant food product release, and the domestic news media for foreign food quality crisis reports etc. These factors also influence the consumers to buy imported infant food choices.

Overall when buy imported infant food compared to the past blindly obedient, and reckless to suggest that consumers now rational scientific consumption changes is relatively rational. But baby foods imported from generally speaking it is not difficult to find in the consumer psychology is the main choice, use free trade zone in Shanghai direct marketing center of respondents Mr Zhang's words: "even if the import infant food also has some quality problems, but what happened to the domestic infant food quality and safety problems are more afraid, more feel under import infant food is a better choice. Instead,"

\section{Purchasing funnel analysis of imported infant food}

From the survey of consumers and network BBS discussion and my own experience summed up the three channels are most consumers choose to buy imported infant food sources, respectively is: business over import area, the network purchase, act as purchasing agency abroad. Following, according to the survey is to interview the discussion of information on the three channels are analyzed and concluded the corresponding import infant food quality analysis.

Supermarkets import area. In the paragraph of consumer analysis can be learned in consumer choice to the supermarket to buy imported infant food is the most people choose a channel, accounts for nearly $60 \%$ of the proportion. Reason for consumers to choose a super buy imported infant food business are obvious, first of all, business super is one of the traditional purchase channels, consumer to business has formed a business ultra products of good quality inherent point of view, in precisely the consumer has formed the habit of super good to buy authentic products to dealer. And baby foods for consumers but also will be a little careless product, so in business become for their first choice. Second everyone know know any into super import infant foods is after the national inspection and quarantine in order to allow shipments listed, April 1, 2014 was the most strict quarantine measures initiated, the requirements of more and more comprehensive national standards strictly, in this case, super import infant foods nature is consistent with the relevant regulations of the state, is also reassuring products. Seeing is believing, so-called consumers finally go to see the super selected products, see how it packing, buy how much people, and so on believe facts can rest assured to buy. 
Overall business is deeply rooted in the hearts of the people's shopping place, when consumer is in the super buy imported infant foods is directly and safely.

Buying by the network. With the popularity of e-commerce, more and more people accustomed to the network consumption. Facing import infant food, the mohican, major e-commerce sites is emerge in endlessly to launch a variety of means to attract consumers. Literally open the website you're always in the most eye-catching location see food imports, in infant food section, imported infant food is always in the forefront of place. But the network sales channels is one of the most serious problem is that online merchants uneven quality, many online merchants exists the phenomenon of fish in troubled waters cannot guarantee the quality of products sold by them is in conformity with the national standard, or is in their online introduction in infant food is imported. Also there will be a "3 without" and "false" import infant food. After all images and text on the network information is the possibility of fraud is too high, if met with lack of product quality problems and after-sales, consumers' rights and interests cannot be guaranteed. This means that consumers need to practice drawn, the consumer to distinguish whether is available, a liar and fishing sites.

In this case, the web to buy a new: overseas online shopping. As the name suggests overseas online shopping means consumers purchase items directly in the overseas website, and directly sent to the home of the domestic consumers. But overseas online shopping also has his trouble place, first of all, mail, there are some websites, such as iHerb) support for direct shipment to China, which is in the up and down after a single site will send you buy directly to your house ${ }^{[12]}$. But most of the website is not support foreign direct mail to China, then you need a transport company to help. We buy good things from a site to the transport company's warehouse, transport company and sent to our domestic home ${ }^{[12]}$. Then, is the problem of freight, the freight is divided into two kinds: 1 . Domestic freight: general web site can have how many dollars from the United States to buy the full freight, that is from the website to the freight forwarder warehouse, general shopping to round up the amount of free shipping more economical, or risk another freight payable at destination. 2. International freight: transportation company after receiving your stuff to help you send it to the home, this is called international freight ${ }^{[12]}$.

Network as a new channel is more and more mature, for after 80 , living family still has a great attractive, consumers demand the use of the mouse you can easily buy imported infant food, especially the emergence of overseas online shopping is solved consumer desire for authenticity. No wonder online purchase is ranked second in the eyes of consumers choose channel.

The overseas act as purchasing agency.Purchased overseas trend intensified in the past two years, from cosmetic to fashionable household appliances, from America to Korea.Of course affects millions of $\mathrm{m}$ long heart baby foods in the mid-term. More and more parents obligation to look back into the infant food imports to buy on sb's behalf in the spring. Then act as purchasing agency especially import infant food bought abroad it has the charm of how to attract consumers? Himself from the interview the choice of foreign consumers bought some data information: first of all foreign consumers bought proportion about $15 \%$, and almost all the respondents provides an information is addictive bought abroad.

Act as purchasing agency has a variety of advantages, such as product and various optimization. Consumers can directly renminbi settlement, for example, you don't need to worry about the conversion rate. Such as the consumer can ask when send it special delivery of a barrel of milk powder have plastic wrap and airbag separate packing and so on. But it is easy to act as purchasing agency has one of the biggest problems encountered fake act as purchasing agency, consumers are looking for purchasing must distinguish clearly the true and false buy on sb's behalf in case of buy fake imported products. In general, act as purchasing agency is another critical to consumers, as consumers need to differentiate true and false of act as purchasing agency. 


\section{Conclusion}

With the rapid development of the times and the deepening of international exchanges, more and more businesses and consumers participate in the sale of imported infant foods. Coupled with domestic consumers do not trust domestic brands, China's infant food market will usher in more foreign brands. More and more consumer choice, the same problem will appear more and more. Hoping that consumers can solve these problems is my biggest motivation by this paper.

\section{References}

[1] Hong-yue Pan, Rui Lu. Development of infant food supplement industry characteristics and trends[J]. China Food and Nutrition.(2010.04:28-31).in Chinese.

[2] Feasibility study of infant food industry[N]. China Economic Herald.(2014).in Chinese.

[3] http://www.docin.com/p-456967270.html

[4] Chao Li. Our infant food industry quality report[J]. Quality and standardization.(2014).in $\mathrm{C} \quad \mathrm{h} \quad \mathrm{i} \quad \mathrm{n}$

[5] P.G. Clem, M. Rodriguez, J.A. Voigt and C.S. Ashley, U.S. Patent 6,231,666. (2001)

[6] li-yu Chen. Imported milk powder monitoring efforts to "upgrade"[N]. Morning News.(2009).in Chinese.

[7] Chuan-tong Zhang, Juan Lu. Effect of food labeling information to consumers purchasing decisions - with infant food Case[J]. Statistics \& Information Forum.(2012).in Chinese.

[8] Chao Wei.Our infant food industry quality report[J]. Quality and standardization.(2014).in Chinese.

[9] Fang Shu. Stimulate the baby milk powder imported whey powder increased demand for food Shanghai[EB/OL]. LONDON.(2009).in Chinese.

[10] European Heart Network.A Systematic Review of the Research on Consumer Understanding of Nutrition Labelling [M].Brussels,2003

[11] Barreiro-Hurle.Jesus,Does Nutrition Information on Food Products Lead to Healthier Food Choices?[J],Food Policy,2010

[12] http://haitaola.weebly.com

[13] Yi-wen Chu. Study on imports of dairy products in Shanghai major food safety issues[D]. Fudan University.(2011).in Chinese.

[14] Hua Yu. Shanghai Port imported a food safety situation and Supervision Countermeasures[D]. Fudan University.(2012).in Chinese.

[15] An-na Du. What are "imported" milk powder is false?[N].Guangzhou Daily.(2012).in Chinese.

[16] http://home.babytree.com/u1578712892/journal/show/8988389 